\title{
Notice of Retraction: Harada S, Yamazaki Y, and Tokuyama S (2013) Orexin-A Suppresses Postischemic Glucose Intolerance and Neuronal Damage through Hypothalamic Brain-Derived Neurotrophic Factor, J Pharmacol Exp Ther, 344: 276-285; DOI: https://doi.org/10.1124/jpet.112.199604
}

At the request of Dr. Shogo Tokuyama, the article cited above is being retracted. The article coauthors are in agreement with the retraction. The data presented in Fig. 4, C and D, and Fig. 8 was manipulated to affect the conclusions made in the article. The data manipulation was confirmed by an investigative committee at Kobe Gakuin University.

doi.org/10.1124/jpet.112.199604retraction 